\title{
SOBRE LA COPELACIÓN DE LA PLATA EN EL MUNDO TARTÉSICO
}

\section{ON THE CUPELLATION OF SILVER IN THE TARTESSIAN WORLD}

\author{
por \\ ROCÍO IZQUIERDO DE MONTES
}

RESUMEN El registro arqueológico parece apuntar a que la plata tartésica fue obtenida por copelación. En este trabajo estudiaremos dicha técnica metalúrgica: el proceso productivo, los talleres y el origen de la copelación en el Suroeste hispano.

\begin{abstract}
Archaeological record provides evidence to support that tartesic silver was obtained by cupellation. The purpouse of this paper is the study of that metallurgical technique: the process, the workshops and its historical origin in south-west Spain.
\end{abstract}

\section{INTRODUCCIÓN}

"Estando provista dicha región (La Turdetania) con tantos productos se debe elogiar y admirar no menos, sino más, la abundancia de sus metales. Porque todo el país de los Iberos está lleno de ellos, mientras no todo es tan fértil y rico, y menos la región rica en metales. Sucede raras veces que una región sea rica en ambos productos, y también es raro que la misma región en poco espacio sea rica en varios metales. En cuanto a la riqueza de sus metales no es posible exagerar el elogio de la Turdetania y de la región lindante. Porque en ninguna parte del Mundo se ha encontrado hasta hoy ni oro, ni plata, ni cobre, ni hierro en tal cantidad y calidad. ... " (Estrabón III, 2, 8) ${ }^{1}$.

La riqueza metalífera de Tartessos fue de sobras conocida en el mundo antiguo. Las fuentes clásicas así lo reflejan. Para los escritores grecorromanos referirse a Tartessos significaba hablar de metales, y muy especialmente de plata. Mitos, leyendas y topónimos aluden a su excelencia argentífera, encontrándonos un Mons Argentarius (Avieno 291), un rey de nombre Gerión que nació frente a Erytheia, junto al río Tartessos, de raíces argénteas (Estesícoro en Estrabón III, 2, 11), etc. Los textos también cuentan que fenicios (Diodoro V, 35, 4-5) y griegos (Heródoto IV, 152; I, 163) cruzaron con sus naves el Mediterráneo en busca

1. Traducción de A. Schulten (1952: 98). 
de la plata de Tartessos. Una vez producido el ocaso de dicha cultura y pasado ya mucho tiempo, como indica el texto que abre el presente trabajo, sigue siendo bien apreciada la riqueza metalífera de la Turdetania, territorio que tiempo atrás fue el de Tartessos.

El importante papel que jugó la metalurgia de la plata en la economía tartésica no ha pasado desapercibido desde la investigación arqueológica. Durante un tiempo se aludió a ella a partir de lo que plasmaban las fuentes, sin entrar de lleno en cuestiones de minería y técnicas metalúrgicas. La puesta en valor de las minas de Riotinto en el siglo XIX sacó a la luz muchos vestigios de minería y metalurgia antiguas, restos aprovechados por geólogos y eruditos de la zona para el comienzo de la investigación sobre dichos temas con la catalogación de minas y yacimientos (Rua Figueroa 1859; Gonzalo y Tarín 1886-1888). Aparte de algunas intervenciones arqueológicas puntuales en yacimientos del área de Riotinto, el verdadero inicio de una investigación sistemática sobre el tema va de la mano de A. Blanco y B. Rothenberg (1981), quienes a partir del Proyecto Arqueometalúrgico de Huelva estudiaron la geología de la provincia, y con base en los materiales arqueológicos fueron localizando las minas y los poblados o centros metalúrgicos de la Antigüedad. Así quedaron sentadas las bases del trabajo que se ha venido desarrollando en las últimas décadas.

A las primeras excavaciones en el área minera de Riotinto (Blanco y Luzón 1969; Blanco y otros 1969 y 1970) ha venido a sumarse durante los años ochenta una importante labor de campo, que ha permitido ampliar y matizar los conocimientos que sobre minería y metalurgia antiguas se tenían. Se conocen otras áreas mineras que, junto a Riotinto, también fueron exploradas en busca de plata, además de haberse localizado yacimientos en los que se beneficiaba el metal argénteo. El volumen de información recopilado permitió enfocar la investigación hacia cuestiones de tecnología metalúrgica, es decir, a las técnicas aplicadas para obtener el metal noble. Todo parece apuntar a que la plata tartésica es resultado de la copelación, problema que ha dado lugar a una amplísima bibliografía según se verá a lo largo del presente artículo.

Conocidos los focos mineros, los poblados o centros de actividad metalúrgica y la técnica aplicada para beneficiar la plata, actualmente la problemática está centrada en parte en el origen de la copelación. Nuevamente vuelven a confrontarse las posiciones que defienden la autoctonía de dicha técnica (Blanco y Rothenberg 1981; Pérez Macías 1995) y las que sostienen que la copelación, técnica desconocida en el Tartessos precolonial, fue introducida por los fenicios en el Suroeste peninsular (Ruiz Mata 1989; Fernández Jurado 1995).

Dos cuestiones previas deben ser aclaradas antes de precisar los problemas concernientes al origen de dicha técnica: el marco geográfico y los límites cronológicos. El área metalúrgica de Tartessos en sentido estricto se limita al Cinturón Ibérico de Piritas de la Sierra Morena occidental. El contexto cronológico se refiere exclusivamente al Hierro Antiguo, época en que se fechan todos los testimonios arqueológicos tradicionalmente relacionados con la copelación durante la época tartésica. Con relación a este último problema, debemos advertir en este apartado introductorio que nuestras referencias cronológicas se refieren siempre a fechas sin calibrar, tradicionalmente obtenidas a partir de la tipología de los materiales arqueológicos. Hoy, la calibración de las dataciones radiocarbónicas tendería a remontar al menos en un siglo las fechas absolutas aquí propuestas, pero no cambiaría en nada los resultados de nuestra investigación, ya que a una subida general de las fechas finales de la Edad del Bronce (Ruiz-Gálvez 1995; Castro y otros 1996: 208-209) correspondería una paralela elevación de la cronología inicial de la colonización fenicia.

El tema permanece aún abierto para la investigación, y no quedará resuelto al menos mientras no se precisen en mayor medida los procesos técnicos utilizados en la copelación de la plata, así como las referencias cronológicas y culturales en que éstos estaban inmersos. 


\section{DE COPELACIÓN Y COPELAS TARTÉSICAS}

El Cinturón Ibérico de Piritas, franja arqueada de 250 × $35 \mathrm{Km}$, se extiende por el Suroeste peninsular desde la zona occidental de Sevilla hasta bien entrado Portugal. Se conforma así un área minera con menas complejas formadas por agrupaciones de minerales, entre los que figuran el hierro, el cobre, la plata y el oro, todos ellos explotados desde la Antiguiedad (Jones 1981: 31). El mineral extraído hoy tiene leyes de $40 \mathrm{gr} / \mathrm{Tm}$ de plata y $2,5 \mathrm{gr} / \mathrm{Tm}$ de oro, pero en tiempos protohistóricos se procesaron materiales con una relación más alta (Fernández Jurado 1993: 140).

Si durante un tiempo el foco de Riotinto se consideró el gran centro minero tartésico -protagonismo indiscutible-, el mayor volumen de datos arqueológicos y el análisis de muestras de mineral y escorias de fundición han puesto de manifiesto que hay más de un foco minero en funcionamiento. Así, se valorará también la importancia del núcleo de Aznalcóllar (Sevilla) y del Andévalo occidental (Huelva), y, pendientes de investigar, el de los criaderos de Guadalcanal y Cazalla de la Sierra (Sevilla) y de Plasenzuela y La Motilla (Cáceres) como posibles suministradores de mineral a los centros metalúrgicos tartésicos (Fernández Jurado 1988-89: 210; Rovira 1995: 484).

El mineral extraído era llevado a las áreas de trabajo del metal. El estudio analítico de escorias procedentes de yacimientos tartésicos pone de manifiesto que el beneficio de la plata podía llevarse a cabo tanto en los focos mineros como en puntos más alejados de éstos. Para Fernández Jurado (1993: 140-142) es determinante la necesidad de combustible, ya que las zonas de minas son deficitarias en arbolado; por otro lado, este traslado abarata los costes de producción, ya que, al ser el propio centro metalúrgico el punto comercial, se ahorran gastos en portes. De otra manera, sería necesario acarrear combustible a la zona de minas, y después, una vez beneficiada la plata, habría que transportarla con un importante y caro dispositivo de seguridad.

\section{La Técnica}

Aun con algunos pormenores necesitados de mayor precisión según han señalado algunos autores (Pérez Macías 1991: 105; Rovira 1995: 486), la definición más explícita del proceso de copelación de la plata en época tartésica la ha dado Fernández Jurado (1993: 146). Constaba de dos fases: la fusión y la copelación propiamente dicha.

La fusión consistía en colocar el mineral molido junto con el fundente y someterlos a la acción del fuego. Así resultaban dos productos: la escoria y el régulo. Este último constituía en realidad un conjunto de plomo, plata y oro, con restos de otros elementos. En este primer paso el plomo actúa como captador de metales nobles.

Con el proceso de copelación posterior, el régulo se colocaba en una copela y se exponía a la acción del fuego para dejar libre los metales nobles. El plomo quedaba liberado a la atmósfera y adherido en forma de litargirio (óxido de plomo) a las paredes del cuenco usado como copela.

Las técnicas que intervenían en el proceso necesitaban una infraestructura determinada, de la que formaban parte tanto utensilios específicos como dependencias concretas.

En Tejada la Vieja (Escacena del Campo), en una zona del yacimiento próxima a la muralla, se excavaron unas estancias de piedra que conformaban un espacio rectangular. La abundancia de restos de actividad metalúrgica de las inmediaciones llevó a interpretarlas como un "lavadero de mineral". La anchura de los muros hacía descartar su uso como abrevadero de animales, haciendo de aquel espacio un lugar destinado al preparado del mineral previamente a su fundición (Fernández Jurado 1987: 112, fig. 26). 
El mineral extraído para beneficiar plata era el gossan en el caso del procedente del área de Aznalcóllar (Ruiz Mata y Fernández Jurado 1986: 267-268), y la jarosita argentífera en el de Riotinto (Hunt 1988: 147). Como fundente se utilizó sílice (Blanco y otros 1969: 157).

En las excavaciones en las que se han detectado áreas de trabajo metalúrgico se han constatado varios tipos de hornos que se destinaron a la fusión del mineral de plata. En el casco urbano de Huelva, concretamente en la excavación practicada en el solar $n^{\circ} 6$ de la calle Puerto, aparecieron dos hornos de fundición, si bien sólo uno de ellos pudo excavarse por completo. Éste presentaba planta circular de 1,50 m de diámetro interior, circundando su perímetro un anillo de cantos de río, bloques calizos y algunas lajas de pizarra que conformaban su base. La estructura estaba ligeramente basculada al Suroeste, aprovechando la dirección de los vientos dominantes en Huelva. Con esta inclinación, el poyete en el que se recogía el metal fundido se encontraba a una cota inferior a la del resto del horno, el cual se cargaba con capas alternas de mineral con el fundente y combustible, recubriéndose toda la estructura con una cúpula en la que se dejaba un orificio a modo de respiradero. Esta cubierta era desmontada cada vez que finalizaba la hornada. Las toberas se colocaban en cualquier parte del horno, siempre y cuando no fuese en el lado respetado para descarga de la masa fundida (Fernández Jurado 1988-89: 183-185).

La viabilidad de estos hornos ha sido cuestionada por Rovira (1995: 485), para quien el diámetro interior de la estructura sería demasiado ancho como para estar ocupado en su totalidad por la cámara de fundición, lo que impediría alcanzar y mantener una temperatura de $1.100^{\circ} \mathrm{C}$, que es la indicada para fundir la carga. Tampoco la cubierta podría ser semicircular, resultando más factible una cilíndrica como corresponde a un horno de chimenea, el adecuado para fundir de manẹra correcta minerales de este tipo.

Un segundo modelo de horno es el encontrado en la excavación de San Bartolomé de Almonte (Huelva). Consiste en una estructura de tendencia circular excavada en el terreno natural con diámetros diversos. En algún caso (fondo XV) se revoca con arcilla la base, mientras que en otro (fondo I.1) se recogieron restos de adobe que posiblemente formaban parte de la cubierta del horno, en el caso de que fuese cubierto, o quizás de un murete que protegía a los operarios durante el proceso de fundición, siempre y cuando el horno no se cubriese (Ruiz Mata y Fernández Jurado 1986: 259). También se ha cuestionado la función como hornos de estas estructuras, porque no cumplirían los requisitos básicos -tamaño y diseño adecuadosy porque los rellenos que colmatan dichas estructuras consisten en escorias, cenizas y otros materiales relacionados con la metalurgia, pero también con otras funciones ajenas a dicha labor, por lo que podría tratarse de simples basureros (Rovira 1995: 485).

En el Cerro Salomón (Riotinto) no se detectó ningún horno, pero en el interior de las viviendas solían aparecer restos de carbón, cenizas y escorias junto a hogares, de ahí que se propusieran como hornos unos hoyos abiertos en el suelo con unos $70 \mathrm{~cm}$ de diámetro y las paredes revocadas de arcilla. El horno se cargaba con el mineral, el fundente y el combustible. La carga fundida y enfriada se recogía del fondo de la estructura (Blanco y Luzón 1969: 129; Blanco y otros 1969: 157, fig. 36).

Los hornos del Cerro Salomón son parecidos a los de San Bartolomé salvo en el tamaño, lo que no invalida la función como hornos de las estructuras almonteñas si consideramos las cantidades de metal a beneficiar en cada caso. El tamaño debe de estar relacionado con la cantidad de carga a fundir, con lo que resulta más necesario el equilibrio de proporciones que las medidas absolutas de la estructura. En cualquier caso, un horno arruinado puede ser también usado como basurero, dando así otra explicación posible a los materiales no relacionados con la metalurgia que contenían las estructuras de San Bartolomé.

En el interior del horno se ha de mantener una temperatura constante para fundir el mineral. Esto se consigue mediante el aire que insuflan las toberas a partir de la acción de un fuelle (Fernández Jurado y Ruiz Mata 1985: 28). Consisten éstas en unos tubos de arcilla de sección circular y forma generalmente de cuerno, aunque también las hay de doble tubo como las procedentes del Cerro Salomón, que coinciden con las de Toscanos y Castillo de Doña Blanca, toberas éstas de origen fenicio (Ruiz Mata 1989: 237). 
En Huelva y Tejada la Vieja se asocia la aparición de toberas con la de unos ladrillos de sección triangular que posiblemente se usaron para calzar aquéllas en la boca del horno (Fernández Jurado 1988-89: 159, lám. LXXII, 24).

Al fundirse el mineral y pasar a estado líquido para después enfriarse y solidificarse, las toberas presentan su superficie exterior escorificada y con irisaciones amarillentas producto de la oxidación del plomo (Blanco y otros 1969: 157; Pérez Macías 1991: 102).

El resultado final de la fusión es la obtención de un régulo de plomo argentífero, ya que en esta parte del proceso el plomo actúa como captador de metales nobles (la plata y el oro). Según se ve, el plomo es un elemento fundamental para la buena consecución del beneficio de la plata.

Si el mineral extraído de la mina presenta plomo en su composición es perfectamente viable comenzar la fusión, pero si no lo contiene, será necesario añadírselo entre los "ingredientes" que participan en la primera parte de la copelación de la plata. En yacimientos como San Bartolomé de Almonte y Huelva se ha encontrado plomo metálico que posiblemente se añadió a la carga en el proceso de fusión (Ruiz Mata y Fernández Jurado 1986: 257; Fernández Jurado 1988-89: 191).

Pocos régulos de plomo argentífero se han encontrado en yacimientos tartésicos. Entre ellos dos muestras procedentes de Peñalosa (Escacena del Campo) publicadas por Fernández Jurado (1993: 165) pueden considerarse por su contenido de $0,9 \%$ de plata $(9.000 \mathrm{gr} / \mathrm{Tm}$ ) como tales (Rovira 1995: 486).

En el proceso de copelación propiamente dicho, el régulo de plomo argentífero se deposita en una copela y se somete a la acción del fuego para liberar del régulo todo contenido plúmbeo. Como antes señalamos, parte de éste pasa al aire en forma de óxido y otra queda adherida al fondo de la copela.

Aunque se ha escrito mucho sobre copelación y copelas tartésicas, en la práctica pocas de estas últimas piezas se han encontrado. Se han propuesto varios tipos:

- Basándose en técnicas referidas por un orfebre del siglo XVI y por las que actualmente se siguen en laboratorio, un tipo de copela se prepararía con huesos quemados y triturados mezclados con cal y agua. La amalgama se introduce en pequeños moldes, se aprieta y deja secar para, finalmente, romper el molde y sacar la copela. La aparición de unas piezas de cerámica con sus paredes perforadas y pequeño tamaño asociadas a restos de actividad metalúrgica, ha llevado a interpretar esos "coladores" como moldes de copelas. La ausencia de restos óseos en yacimientos como San Bartolomé, poblado metalúrgico, hace suponer que los huesos se aprovecharon para la preparación de las copelas (Ruiz Mata y Fernández Jurado 1986: 256-259, lám. LXIX, 967 y 970). El hecho de que no se haya encontrado hasta este momento resto alguno de las copelas de huesos y cal, hace que se considere esta interpretación una mera hipótesis de trabajo.

- Las aparición de fragmentos de vasijas con escorias adheridas en contextos metalúrgicos, parece responder a que se usaban también como copelas recipientes abiertos de cerámica en los que se depositaba el régulo de plomo argentífero y se sometía a la acción del fuego. Finalmente, queda parte del plomo liberado junto a otros elementos adheridos en el fondo del tiesto. Éstas sí que parecen ser los recipientes usados en la obtención de plata. Están presentes en yacimientos metalúrgicos como San Bartolomé (Ruiz Mata y Fernández Jurado 1986: 257) y Tejada la Vieja (Fernández Jurado 1987: 130, lám. XCII, 11). En la excavación del solar $\mathbf{n}^{\circ} 9$ de la calle Puerto (Huelva) (nivel IIb) se encontró un fragmento de cazoleta muy pesada con restos de arcilla quemada en su exterior. Tal vez se trate de una copela por su alto contenido en plomo (37,02 \%) (Fernández Jurado 1988-89: 191). Otro fragmento cerámico con plomo adherido en su cara interna procede de una cabaña de La Puebla del Río, en la provincia de Sevilla (Escacena y Henares e.p.). En el yacimiento de Monte Romero (Almonaster la Real) se recogieron doce copelas casi completas. Consisten en unos vasos de cerámica en forma parabólica con el borde engrosado. El interior presenta adheridas varias capas de plomo. Algunas piezas absorbieron tanto plomo que casi puede considerarse éste su elemento base (Pérez Macías 1991: 103, fig. 3). 
Los hornos de copelación son mal conocidos. Parece que consistieron en simples hogares al modo de las fraguas de herrero, en los que se depositaban las copelas, con el régulo en su interior, y se sometían a la acción del fuego (Rovira 1995: 486). En este trabajo también eran necesarias toberas que mantuviesen la temperatura adecuada para la fusión del plomo. Su forma no difiere de la que presentaban los hornos de fundición, pero en este caso la cara exterior no tiene escoria alguna sino la superficie quemada por el fuego (Pérez Macías 1991: 104).

El plomo resultante de la copelación queda en forma de litargirio. En Monte Romero se detectaron las rebabas de este óxido de plomo resultante de la copelación (Pérez Macías 1991: 104). El análisis por Difracción de Rayos $\mathrm{X}$ al que ha sido sometido un fragmento de copela procedente de la excavación en C/ Puerto 9 de Huelva, también ha identificado litargirio entre los elementos que lo conforman (Hunt 1995: 452 , fig. 2).

\section{Centros metalúrgicos}

Desde las primeras excavaciones en el Cerro Salomón (Riotinto) a finales de los años sesenta (Blanco y otros 1969 y 1970), han venido a sumarse otras muchas que han permitido ampliar enormemente los conocimientos que sobre metalurgia de la plata se tenían. En este apartado expondremos aquellos yacimientos en los que hay evidencias de haberse copelado plata, ya sea con fusión o sin ella, y dejamos sin tratar aquellos otros en los que se llevó a cabo únicamente el proceso de fusión. Tampoco incluiremos los sitios en los que la actividad metalúrgica se conozca a partir de prospecciones, ya que el objetivo que perseguimos es el de situar la copelación no sólo en el espacio, sino también en el tiempo, y para ello es fundamental que los datos estén bien contextualizados. De Norte a Sur los yacimientos son los que siguen:

1. Monte Romero (Almonaster la Real, Huelva). Este yacimiento fue localizado durante las labores de exploración del Proyecto Arqueometalúrgico de Huelva, y se asoció, por sus escorias y materiales arqueológicos, a dos épocas y metalurgias bien distintas, una del cobre durante el Calcolítico y otra de la plata durante el Período Orientalizante (Blanco y Rothenberg 1981: 84-85). Las excavaciones practicadas durante los años ochenta desdicen aquella primera interpretación, ya que se trataría de un lugar de trabajo metalúrgico fechable sólo en el segundo momento, que recoge todo el proceso de copelación de la plata, desde la tostación del mineral como paso previo a su fusión hasta la copelación, con la recogida de doce copelas con cantidades importantes de plomo absorbido y rebabas de litargirio. Los materiales arqueológicos del contexto en que se datan los trabajos metalúrgicos consisten en vasos con decoración de impresiones digitales, recipientes con forma de cono invertido, ánforas de saco fenicias y un cuenco de cerámica gris. A partir de éstos se fecha el yacimiento entre mediados del siglo VII y principios del VI a.C. (Rothenberg y otros 1986: 1-4; Pérez Macías 1991: 102-107).

2. Riotinto (Huelva). En el sector de la Corta del Lago, Blanco y Rothenberg (1981: 104-107) señalan la presencia de "fragmentos de hornos", escoria de plata y crisoles. Las escorias se documentaron en niveles atribuidos por los excavadores al Bronce Final prefenicio; no obstante, F. Amores (1988: 742-748), a quien se le encargó el estudio de los materiales arqueológicos, ha indicado posteriormente que su informe preliminar fue erróneo debido a que no contó con toda la documentación de las excavaciones, y que el estrato inferior contenía de hecho ánforas fenicias. Por tanto, la cronología más antigua de este yacimiento no puede ser remontada de momento a tiempos anteriores a la colonización fenicia.

En Cerro Salomón, la existencia de copelación se deduce de las escorias con alto contenido argénteo y de las gotas de plomo derretido que aparecen en el interior de las viviendas. Asimismo, la presencia de 
altas concentraciones de ceniza, de carbón y de huesos quemados, entre otros testimonios, denota la posible presencia de hornos. La cultura material que acompaña a las evidencias de metalurgia consisten en ánforas de saco, lucernas de uno o dos picos, ampollas, etc., que fechan aquellos trabajos durante los siglos VIII y VII a.C. (Blanco y Luzón 1969: 126-130; Blanco y otros 1970: 13-14).

3. Tejada la Vieja (Escacena del Campo, Huelva). El yacimiento fue excavado primeramente dentro del Proyecto Arqueometalúrgico de Huelva (Blanco y Rothenberg 1981:229-282) y después por el equipo de J. Fernández Jurado (1987). Este último investigador ha sugerido la existencia de una producción doméstica de la plata no orientada a fines industriales o comerciales. Las escorias, toberas, "coladores" y cerámicas con escorias adheridas son pruebas suficientes de copelación de la plata (Fernández Jurado 1987: 126-137). Parece que Tejada actuó como centro redistribuidor del mineral extraído en el área de Aznalcóllar, más que como lugar en el que la actividad fundamental fuese la metalurgia. El sitio se ocupa por primera vez a finales del siglo VIII a.C., por lo que carece de asentamiento indígena precolonial (Fernández Jurado 1987: 153-169).

4. Peñalosa (Escacena del Campo, Huelva). Poblado abierto de cabañas a $4 \mathrm{Km}$ de Tejada. Se constata metalurgia de la plata a partir de las escorias, toberas, "coladores" y cerámicas con escorias adheridas que aparecen en la mayoría de las estructuras excavadas. El inicio de las actividades metalúrgicas coincide con la aparición de cerámica a torno -concretamente un cuenco de barniz rojo-, lo que lleva a fechar ese momento hacia el 750 a.C., poco antes de la fundación de Tejada, que es justamente cuando se abandona Peñalosa (Fernández Jurado y otros 1990: 188-189).

5. Niebla. Los datos sobre metalurgia de plata proceden de la zona de la Puerta de Sevilla. Consisten en escorias y fragmentos de "crisoles". Dichos elementos se recuperaron en el estrato inferior, que se fecha en el siglo VII a.C. (Belén y Escacena 1990: 229 y 234). Pingel (1975: fig. 6:17) había recogido ya en el "Desembarcadero", junto al río Tinto, un fragmento de "colador" de cerámica a mano.

6. San Bartolomé (Almonte, Huelva). Poblado abierto formado por estructuras excavadas en la roca natural y que se reparten por el espacio dispuestas en grupos. La metalurgia de la plata queda constatada por los hornos, toberas, escorias, "coladores", cerámicas con escorias adheridas, plomo metálico y bloques de caliza que se usaron como fundente, evidencias que remiten tanto a la fusión como a la copelación (Ruiz Mata y Fernández Jurado 1986: 256-259). Las actividades metalúrgicas están presentes sólo en las estructuras que contienen cerámica a torno, por lo que deben fecharse en época colonial, en concreto no antes de mediados del siglo VIII a.C. según han sugerido los excavadores (Ruiz Mata y Fernández Jurado 1986: 257).

7. Huelva. Las excavaciones que en los últimos años se han venido realizando en su casco antiguo, han sacado a la luz una ciudad en la que su actividad económica fundamental en época tartésica era la metalurgia de la plata. Avales suficientes resultan las escorias, restos de mineral, hornos de fundición, toberas, "coladores", cerámicas con escorias adheridas y fragmentos de plomo metálico que aparecen en el transcurso de los trabajos arqueológicos (Fernández Jurado 1988-89: 113-193). Sobre el inicio de la metalurgia de la plata debemos apuntar que coincide con el comienzo de la presencia fenicia a mediados del siglo VIII a.C. (Fernández Jurado 1988-89: 292).

8. Cerro de la Albina (La Puebla del Río, Sevilla). En las proximidades de la orilla del golfo tartésico que citan las fuentes antiguas, se excavó un fondo de cabaña en el que se detectaron materiales para la extracción de plata, como "coladores" y un fragmento de copela con óxido de plomo adherido en su cara 
interna. Estos trabajos se fechan durante el siglo VII a.C. por los útiles de hierro, un ánfora y un fragmento de un plato de barniz rojo fenicios que pertenecen al momento de ocupación de la cabaña (Escacena y Henares e.p.) ${ }^{2}$.

9. Campillo (El Puerto de Santa María, Cádiz). En la cabaña $n^{\circ} 1$ de este yacimiento aparecieron abundantes escorias y coladores de cerámica -alguno como los de San Bartolomé de Almonte-, si bien los autores de la excavación no dejan clara la existencia de actividades metalúrgicas (López Amador y otros 1996: 62-63, 68, 74, etc.). Aunque su cronología ha sido llevada hasta el siglo Xa.C. en fechas no calibradas, la existencia de cerámica a torno y de un cuchillo de hierro desde la base de la estratigrafía interna del fondo de cabaña, aconseja datar la estructura y las actividades en ella constatadas ya en época colonial. De hecho, Ruiz Mata (1994: 298-299) ha señalado que los paralelos tipológicos de la cerámica a torno de Campillo se encuentran en niveles del siglo VIII a.C. del asentamiento fenicio de Doña Blanca.

\section{EL ORIGEN DE LA COPELACIÓN DE LA PLATA EN EL TERRITORIO DE TARTESSOS}

Que el Suroeste ibérico fue rico en metales, y que entre ellos figuraba la plata demandada por los fenicios, es algo de sobras demostrado. Pero esta afirmación genérica está necesitada de puntualizaciones acerca de cuándo dicho metal comenzó a explotarse y de la tecnología con que se recuperó. Para ambos aspectos la investigación está dividida entre quienes defienden procesos locales y quienes dan más importancia al impacto foráneo. Por una parte, y por lo que se refiere al Suroeste ibérico, se ha defendido un origen del uso de la plata y de la técnica de la copelación en el Bronce Medio local, de manera que habría continuidad desde esta fase hasta los tiempos tartésicos. Por otra, se ha propuesto la introducción de la copelación por parte de los fenicios a partir del siglo VIII a.C., afirmando paralelamente que la plata anterior no fue copelada.

\section{Los primeros metalurgistas de la plata}

Los trabajos de Blanco y Rothenberg (1981) en la provincia de Huelva marcaron durante un tiempo la trayectoria a seguir por la investigación arqueometalúrgica tartésica. Algunas de sus conclusiones han sido superadas porque, evidentemente, el volumen de trabajo que desde entonces se ha realizado ha permitido matizar o corregir aquellas primeras hipótesis. En cambio, otras siguen en pie e incluso se han reforzado con nuevos datos producto de la investigación actual. Respecto a la copelación de la plata, Blanco y Rothenberg (1981: 171) propusieron el conocimiento de dicha técnica metalúrgica con anterioridad al impacto oriental en el siglo VIII a.C. Para ellos, Tartessos constituía una cultura autóctona heredera de la megalítica y de la argárica, y los conocimientos en minería y metalurgia se remontarían hasta aquella primera. De hecho, hoy sabemos que el comienzo de la metalurgia de la plata tuvo lugar en época argárica. Dichos autores reconocieron una ausencia de testimonios que demostraran la existencia de trabajos mineros y metalúrgicos para aquellas fechas pretartésicas, aunque la riqueza en plata del foco de Riotinto no hubiera pasado desapercibida para los "mineros argáricos". Creyeron ver, tanto en la ubicación de la necrópolis de La Parrita (Nerva) como en la presencia de plata entre los ajuares funerarios de las cistas del Suroeste, señales claras del interés mostrado por las poblaciones de inicios del II milenio a.C. por la riqueza minera

2. Agradecemos a los autores de este informe el haber podido disponer del mismo para nuestro trabajo. Los datos están referidos a una intervención arqueológica de urgencia del equipo del Proyecto Estuario (Secuencia Cultural y Análisis del Poblamiento durante el Holoceno en la Antigua Desembocadura del Guadalquivir), del que forma parte la autora del presente artículo. Dicho proyecto, dirigido por J.L. Escacena, está aprobado y subvencionado por la Consejería de Cultura de la Junta de Andalucía. 
de la región (Blanco y Rothenberg 1981:115). Dos factores influirían en la ausencia significativa de documentación: el pequeño volumen de extracción minera y producción metalúrgica típico de una fase de tanteos y ensayos, por un lado, y la destrucción de esas evidencias por remociones posteriores, por otro. Será en el Bronce Final, denominado Tardío por los autores, cuando se relance la producción argentífera en el foco minero de Riotinto. No en vano, en los niveles inferiores de la Corta del Lago las escorias de plata pondrían de manifiesto la pericia alcanzada por los metalúrgicos en la aplicación de una técnica tan complicada como la copelación. Así, al llegar los fenicios la metalurgia de la plata tartésica estaría en pleno funcionamiento y, según mostrarían las escorias de momentos supuestamente anteriores al impacto oriental con respecto a las del Período Orientalizante, no habría diferencia tecnológica alguna. La entrada en contacto entre tartesios y fenicios, vista de esa manera, no llevaría consigo novedad ni minera ni metalúrgica alguna. Los fenicios no serían grandes conocedores ni transmisores de dichas técnicas en tanto que en su país de procedencia faltarían las minas. Los fenicios serían exclusivamente navegantes, comerciantes y artesanos, pero no mineros ni metalúrgicos. No serían éstos los que introdujeron la técnica de la copelación de la plata en Tartessos (Blanco y Rothenberg 1981: 171-173).

El testigo de aquellos trabajos ha sido recogido por J.A. Pérez Macías (1995), que ha reforzado aquella hipótesis con fuertes argumentos: se aplica la copelación como técnica para beneficiar minerales de plata antes de la llegada de los fenicios a suelo peninsular ibérico. Hay correcciones a la cronología y terminología de los trabajos de Blanco y Rothenberg, pero la sustancia es la misma. El inicio de la copelación de la plata se remontaría a plena Edad del Bronce (mediados del II milenio a.C.), en coincidencia con el horizonte de las cistas de Huelva. En ese momento comenzarían a aparecer objetos de plata entre los ajuares funerarios depositados en las cistas, a la vez que también se documentarían restos de trabajos metalúrgicos que evidenciarían la aplicación -eso sí, incipiente- de la copelación como técnica para la obtención de plata. La necrópolis de La Parrita (Nerva) y el poblado del Cerro de Tres Águilas (Minas de Riotinto) son las bazas fundamentales en las que se sostiene su argumentación. De la necrópolis proceden escorias con un alto contenido en plata $(1.775 \mathrm{gr} / \mathrm{Tm})$ y plomo $(0,22 \%)$, y una copela con adherencias metálicas en su interior con un alto porcentaje de plomo ( $\mathrm{Pb} 613 \mathrm{ppm}$ y $\mathrm{Ag} 273 \mathrm{ppm})$ aparecida en superficie en una zona con restos de carbón; tanto unas como otra evidenciarían metalurgia de plata, si bien en un estadio rudimentario como el que corresponde a los inicios del desarrollo que después en tiempos protohistóricos se alcanzará (Pérez Macías y Frías 1989: 13-14; Pérez Macías 1995: 431-432). En el Cerro de Tres Águilas, también fechado en el Bronce Pleno, se encontraron restos de gossan, escorias, copelas y moldes. Los resultados de la analítica no contradicen los de La Parrita, y se sostiene, por tanto, el inicio de la copelación de la plata en el Suroeste peninsular desde el Bronce Pleno (Pérez Macías 1995: 432-434). Ahora bien, como ya apuntaron Blanco y Rothenberg (1981: 170), faltan testimonios de actividad minera y metalúrgica en el tránsito del Bronce Pleno al Final y muy especialmente en el momento anterior al impacto fenicio. Para Pérez Macías (1995: 434-435) este vacío ha sido el que ha provocado que se les adjudicase a los fenicios el papel de introductores de la copelación de la plata en el Suroeste peninsular. Los fenicios habrían tenido referencia de la plata de Tartessos conocida en el Mediterráneo oriental desde época micénica, y comenzarían su empresa colonial durante el Bronce Final en busca de dicha producción argéntea, que alcanzaría niveles industriales en el Período Orientalizante.

Pérez Macías defiende que la continuidad de la producción de plata por copelación desde el Bronce Pleno hasta época tartésica precolonial se apoyaría en el hecho de que las escorias de plata con alto contenido en plomo están presentes en los dos momentos. Éste sería "el mejor argumento a favor de la copelación como elemento fundamental para separarla (se refiere a la plata) de otros minerales" (Pérez Macías 1995: 435).

S. Rovira (1995: 479-480) también sostiene que se copelaba plata con anterioridad a Época Orientalizante, pero los inicios de la aplicación de esa técnica no los remonta a mediados del II milenio a.C. Ciertamente hay piezas de plata en los ajuares de las tumbas del Bronce Pleno, pero ese metal no sería plata copelada, 
sino plata nativa u obtenida a partir de la fundición de minerales de plata fácilmente beneficiables. Por su alto contenido en plata, al autor le extrañan los datos de los análisis llevados a cabo a las escorias y a la copela de La Parrita, sobre todo para tratarse de evidencias de copelación; de ahí que considere "atípicos" dichos resultados y ponga en duda que demuestren el uso de dicho procedimiento técnico. Así pues, tanto las piezas de plata depositadas en las necrópolis de cistas en calidad de ajuares funerarios como los restos de actividad metalúrgica de La Parrita, más bien habrían de considerarse producto del beneficio de minerales de plata que no necesitaban copelación. Pero la importante actividad minera posterior en el foco de Riotinto no habría dejado vestigio alguno de ese mineral (Rovira 1995: 480).

Añade Rovira que el panorama cambiaría en el Bronce Final, época en que se constataría beneficio de la plata por copelación. Eso mostrarían los niveles de base de la Corta del Lago, supuestamente anteriores a la presencia fenicia según dicho autor. Las escorias de Época Precolonial presentarían una composición idéntica a las de Época Orientalizante. Así pues, se copelaba plata "antes de que se dejara sentir el vigoroso influjo oriental" en Tartessos (Rovira 1995: 480). La copelación se habría introducido en suelo tartésico dentro de esa etapa mal conocida que es la Precolonización, pero ¿por quién? (Rovira 1995: nota 35). Nuevamente se sostiene que los fenicios cruzan con sus naves el Mediterráneo una vez que oyen rumores de la plata que se está produciendo en Tartessos.

\section{Los otros metalurgistas de la plata}

Una segunda hipótesis sobre el origen de la copelación vincula a los fenicios con la introducción de esa técnica metalúrgica en el Suroeste peninsular. De esta manera, la copelación se presenta como una de tantas innovaciones que llegan de la mano de los fenicios a Tartessos. Ruiz Mata y Fernández Jurado se han pronunciado, juntos o individualmente, sobre esta cuestión.

El punto de partida y base en la que se asienta el origen foráneo de esta técnica para la producción de plata está en que coinciden cronológicamente la aparición de evidencias que remiten a la copelación (ya sea fusión o copelación propiamente dicha) y la de materiales que ponen de manifiesto que tartesios y fenicios habían entrado en contacto, momentos que se fechan en torno a mediados del siglo VIII a.C. Así se observa en yacimientos como Cerro Salomón, Quebrantahuesos, San Bartolomé de Almonte, Tejada, Huelva o Peñalosa (Ruiz Mata 1989: 235; Fernández Jurado 1995: 413). Sobre la existencia de plata en fechas anteriores al Período Orientalizante, se admite que hay de hecho metalurgia argentífera, pero no se habría aplicado la técnica de la copelación (Fernández Jurado 1995: 414).

A la hora de sustentar y argumentar la introducción de dicha técnica en Tartessos por los colonos orientales, con base en el análisis de las fuentes escritas Ruiz Mata (1989: 209-210) apunta que desde tiempos de Hiram I los fenicios desarrollan toda una empresa comercial en busca de materias primas, productos exóticos y metales, con centro de operaciones en el Mar Rojo. A partir del siglo IX a.C., el objetivo sigue estando fundamentado en los metales (plata y cobre), pero el campo de operaciones estará en Grecia y Chipre; y ya desde mediados de la centuria siguiente la diáspora fenicia alcanzará el Suroeste ibérico. En relación con la supuesta copelación de plata en yacimientos tartésicos con anterioridad a época colonial, señala el mismo autor que en los niveles inferiores de la Corta del Lago, aquellos que Blanco y Rothenberg (1981: 171) asociaron a época prefenicia, concretamente al Bronce Tardío (siglos XII-IX a.C.), es cierto que el porcentaje predominante de cerámicas es indígena, pero también hay ánforas fenicias, con lo cual es insostenible que dichos niveles sean precoloniales, y que, por tanto, se lleve a cabo copelación de la plata con anterioridad al impacto oriental (Ruiz Mata 1989: 233). Además, acerca de la supuesta ignorancia de los fenicios en minería y metalurgia que Blanco y Rothenberg (1981: 173) adujeron por la inexistencia en Fenicia de minas, señala Ruiz Mata (1989: 235) que en el Laurion se copela plata en el siglo IX a.C., 
en coincidencia con la llegada de fenicios al Ática, y añade que en el poblado de Thorikos, en una habitación de época geométrica, se encontrarón dos cubetas, conteniendo una de ellas bloques de litargirio. Por lo tanto, los fenicios contarían con conocimientos técnicos que les habrían permitido enseñar a los tartesios, más adiestrados en la metalurgia del cobre y del bronce, el modo de beneficiar los minerales de plata, objetivo fundamental que mueve a los orientales a cruzar el Mediterráneo.

\section{Entre unos y otros, ¿qué nos queda?}

La plata de época tartésica fue, en consecuencia, o producto de todo un bagaje tecnológico que se retrotrae hasta el Bronce Pleno, o consecuencia de la enseñanza de la técnica necesaria para su obtención de manos de los fenicios. Un análisis crítico del registro arqueológico y una pausada lectura de las fuentes escritas puede aclarar toda esta problemática.

En la etapa tartésica precolonial no contamos con evidencia arqueológica alguna que se asocie a la aplicación, no ya de la técnica de la copelación, sino de cualquier otra que concluya en la obtención de plata. En esos momentos se conoce el inicio del uso del bronce binario en contraposición a los cobres arsenicados del Bronce Pleno (Rovira 1995: 52-54), lo que demuestra un alto conocimiento de determinadas técnicas metalúrgicas, pero ninguna de ellas en relación con la plata. De los yacimientos antes reseñados, los de tiempos tartésicos en los que se constata copelación se encuadran todos en el Período Orientalizante.

Las fuentes escritas antiguas también arrojan luz en torno al origen de la metalurgia de la plata en Tartessos. Tiro había de pagar tributos a Asiria, y entre los bienes que aportaba figuraba la plata (Ezequiel 27, 1-26). También sabemos que desde el siglo IX a.C. los fenicios se dirigen hacia Chipre y el Ática en busca de metales entre otras cosas (Heródoto IV, 47), y en la centuria siguiente acceden al Suroeste de la Península Ibérica. Allí encontrarían poblaciones que conocían sobradamente la metalurgia del cobre y sus aleaciones con otros metales para la obtención de distintos tipos de bronces, pero que, como demuestra el registro arqueológico, no usaban la plata. El pasaje de Diodoro que a continuación recogemos demuestra precisamente que el uso de este metal noble y las técnicas para obtenerlo eran desconocidas en la Península Ibérica entre las poblaciones inmediatamente precoloniales:

\footnotetext{
"Habiendo hablado de Iberia, parece conveniente mencionar sus minas de plata, ya que este país es el más rico en este metal, procurando grandes ingresos a los explotadores...Como en ellos (los Pirineos) existían muchos bosques frondosos, los pastores les habían prendido fuego -según dicen- mucho tiempo atrás, de tal modo que se había quemado el bosque en toda la sierra. Después de arder muchos días, el fuego quemó también la superficie de la tierra, lo cual dio origen al nombre de Pirineos usado para denominar esas montañas. De la superficie ardiente se deslizó mucha plata, formando los minerales argentíferos, al fundirse, innumerables arroyos de plata pura. Los nativos no sabían explotarla, pero habiéndose enterado los fenicios de este acontecimiento, compraban la plata a cambio de objetos de ínfimo valor. Los fenicios llevaron la plata a Hellas, a Asia y a todos los demás países entonces conocidos, obteniendo así grandes riquezas. Según dicen, fue tal la codicia de los comerciantes, que sustituían las anclas de plomo de sus naves por otras de plata después de que no cabía ya más plata en los buques y todavía sobraba gran cantidad de dicho metal. Este tráfico comercial originó por mucho tiempo un gran aumento del poder de los fenicios, los cuales fundaron muchas colonias, parte en Sicilia y las islas vecinas y parte en Libia, Cerdeña e Iberia" (Diodoro V, 35, 4-5) ${ }^{3}$.
}

3. Tomado de Aubet (1994: 242). La negrita es nuestra. 
El texto, a pesar de tener cierta carga subjetiva, resulta por completo elocuente en lo que se refiere a la introducción del uso de la plata y de las técnicas para obtenerla por parte de los fenicios. Pero ¿qué ocurre entonces con la plata del Bronce Pleno?

En la hipótesis continuísta se supone que en el territorio tartésico se copelaba plata antes de la presencia fenicia. Indudablemente, los datos arqueológicos demuestran que se conocía y valoraba la plata durante el Bronce Pleno, puesto que aparece en objetos de adorno personal depositados como ajuar en tumbas correspondientes al horizonte de las cistas del Suroeste. Igualmente, por la misma época se documentan restos de actividad metalúrgica que se han interpretado como producto del beneficio de la plata, según ha sugerido Pérez Macías (1995: 434). Los territorios del Suroeste habrían conocido la copelación como técnica extractiva de dicho metal (Pérez Macías 1995: 434), de la misma forma que los argáricos por esas fechas (Harrison 1983: 17 y 20). Otros autores, por contra, sostienen que se trataba de plata nativa o bien obtenida de minerales fácilmente beneficiables sin necesidad de acudir a procedimientos de copelación, tanto para el Suroeste (Rovira 1995: 480) como para el Sureste (Arribas y otros 1989: 78). Pero, en nuestra opinión, el problema no radica tanto en admitir o negar dichos conocimientos para el Bronce Pleno, como en explicar por qué, a la llegada de los fenicios, dichos procedimientos habían desaparecido del panorama tecnológico de las poblaciones indígenas.

Si en el Bronce Pleno hay copelación y ésta prosigue hasta Época Orientalizante, ¿qué ocurre con la carencia de documentación tanto minera como metalúrgica existente entre mediados del II milenio y el siglo VIII a.C. con relación a la plata? Parece contradictorio defender la continuidad mientras se admite una ausencia de datos en el tránsito del Bronce Pleno al Final (Blanco y Rothenberg 1981: 115 y 170; Pérez Macías 1995: 434). Entre el Bronce Pleno y el Período Orientalizante median al menos cuatro siglos en los que no contamos con evidencia alguna de metalurgia de la plata. ¿Cómo sostener entonces la existencia de continuidad en dichas labores? Justamente a este vacío o hiato es al que puede achacarse la ruptura entre un mundo y otro, dos horizontes que ni en su cultura material ni en su campo animológico muestran analogía alguna.

La discontinuidad entre el Bronce Pleno y el Bronce Final bajoandaluz ha sido señalada por diversos autores como causa de que el mundo tartésico sea diferente a aquel que enterraba a sus muertos en cistas (Aubet 1986: 58; Belén y Escacena 1995: 72). En un espacio de tiempo tan dilatado es difícil la transmisión de la cultura si no hay continuidad poblacional. Así, aunque en el Bronce Pleno se copelase plata, esos conocimientos de ningún modo pudieron transmitirse a grupos posteriores si el referido hiato tiene como causa un vacío de población. En consecuencia, parece que los tartesios, con anterioridad a la llegada de los orientales, ni trabajaban ni apreciaban la plata, porque simplemente no la conocían. Tal vez la respuesta al enigma que trae de cabeza a más de un investigador esté en la propia lengua tartésica. Si las poblaciones locales no conocían este metal, no tendrían vocablo alguno para referirse a él. El contacto con los fenicios habría desembocado no sólo en un préstamo tecnológico sino también lingüístico a modo de un extranjerismo ${ }^{4}$. Pero, por el momento, la respuesta a la alternativa que planteamos encuentra la misma oscuridad que el vacío que distancia al Bronce Pleno de Tartessos.

4. En contra de esta opinión podría traerse el propio nombre de Argantonio, rey de Tartessos. Pero no sabemos siquiera si este nombre transmitido por las fuentes escritas es indígena, y mucho menos, por tanto, si tiene que ver con la raíz indoeuropea relacionada con el significado de "brillar", luego aplicada al nombre de la plata en griego y latín. Sobre las dudas acerca del nombre de Argantonio y de su filiación lingiuística véase Untermann 1985: 17-18. 


\section{BIBLIOGRAFÍA}

AMORES, F.(1988): "El yacimiento arqueológico de Cortalagos (Río Tinto, Huelva). Datos para una síntesis", 1 Congreso Nacional Cuenca Minera de Río Tinto. Nerva. I Congreso Nacional de la Cuenca Minera de Riotinto

ARRIBAS, A.; CRADDOCK, P.T.; MOLINA, F.; ROTHENBERG, B. y HOOK, D.R. (1989): “Investigación arqueo-metalúrgica en yacimientos de la Edades del Cobre y del Bronce en el Sudeste de Iberia", en Domergue, C. (Coord.): Minería y Metalurgia en las Antiguas Civilizaciones Mediterráneas y Europeas, I: 71-79. Madrid, Ministerio de Cultura.

AUBET, M.E. (1986): "Horizonte cultural protohistórico", Tartessos, extra n 1 de la Revista de Arqueología: 58-73.

- (1994): Tiro y las Colonias Fenicias de Occidente. Barcelona, Crítica.

BLANCO, A. y LUZÓN, J.M. (1969): "Pre-Roman silver miners at Riotinto", Antiquity XLIII: 124-131.

BLANCO, A. y ROTHENBERG, B. (1981): Exploración Arqueometalúrgica de Huelva (EAH). Barcelona, Lábor.

BLANCO, A.; LUZÓN, J.M. y RUIZ MATA, D.(1969): "Panorama tartésico en Andalucía Oriental”, Tartessos y Sus Problemas. VSymposium Internacional de Prehistoria Peninsular: 119-162. Barcelona, Universidad Autónoma.

- (1970): Excavaciones Arqueológicas en el Cerro Salomón (Riotinto, Huelva). Sevilla, Universidad de Sevilla.

BELÉN, M. y ESCACENA, J.L. (1990): "Niebla (Huelva). Excavaciones junto a la Puerta de Sevilla (19781982). La Cata 8”, Huelva Arqueológica XII: 167-305.

-(1995): "Interacción cultural fenicios-indígenas en el Bajo Guadalquivir", Arqueólogos, Historiadores y Filólogos. Homenaje a Fernando Gascó, vol. I, en Kolaios 4: 67-101.

CASTRO, P.V.; LULL, V. y MICÓ, R. (1996): Cronología de la Prehistoria Reciente de la Península Ibérica y Baleares (c.2800-900 cal ANE) (BAR Intern. Ser. 652). Oxford.

ESCACENA, J.L. y HENARES, M.T. (e.p.): "Un fondo de cabaña de época tartésica en La Puebla del Río (Sevilla). (Excavación Arqueológica de Urgencia)", Anuario Arqueológico de Andalucía / 1994. III, Actividades de Urgencia.

FERNÁNDEZ JURADO, J.(1987): “Tejada la Vieja: una ciudad protohistórica”, Huelva Arqueológica IX.

_ (1988-89): "Tartessos y Huelva", Huelva Arqueológica X-XI.

_ (1993): "Plata y plomo en el comercio fenicio-tartésico", Arana, R. y otros (Eds.), Metalurgia en la Península Ibérica Durante el Primer Milenio a.C. Estado Actual de la Investigación: 131-165. Murcia, Universidad de Murcia.

_- (1995): "Economía metalúrgica de Tartessos", Tartessos 25 Años Después (1968-1993): 411-416. Jerez de la Frontera, Ayuntamiento de Jerez.

- y RUIZ MATA, D. (1985): "La metalurgia de la plata en época tartésica en Huelva", Pyrenae 21: 23-44.

FERNÁNDEZJURADO, J.; GARCÍA SANZ, C. y RUFETE, P. (1990): "Prospección con sondeo en Peñalosa

(Escacena, Huelva)", Anuario Arqueológico de Andalucíal 1990. II. Actividades Sistemáticas: 185-190.

GONZALO Y TARÍN, J. (1886-88): Memorias de la Comisión del Mapa Geológico de España. Provincia de Huelva, 2 vols.. Madrid.

HARRISON, R.J. (1983): "Notas sobre el empleo de la plata en la cultura argárica de SE. peninsular", Homenaje al Prof. Martín Almagro Basch, vol. II: 17-21. Madrid, Ministerio de Cultura.

HUNT, M.A. (1988): "La recuperación de la plata del speiss en Río Tinto", Huelva en su Historia 2: 147-160. Huelva, Colegio Universitario de la Rábida. 
(1995): "El foco metalúrgico de Aznalcóllar, Sevilla. Técnicas analíticas aplicadas a la arqueometalurgia del Suroeste de la Península Ibérica”. Tartessos 25 Años Después (1968-1993): 447-473. Jerez de la Frontera, Ayuntamiento de Jerez.

JONES, M.P. (1981): "Los depósitos minerales de la provincia de Huelva”, en Blanco, A. y Rothenberg, B., Exploración Arqueometalúrgica de Huelva (EAH): 31-32. Barcelona, Lábor.

LÓPEZ AMADOR, J.J.; BUENO, P.; RUIZ GIL, J.A. y DE PRADA, M. (1996): Tartesios y fenicios en Campillo. El Puerto de Santa María, Cádiz. Una aportación a la cronología del Bronce Final en el occidente de Europa. Cádiz, Ed. F. Giles.

PÉREZ MACÍAS, J.A. (1991): "La fundición protohistórica de Monte Romero en Almonaster la Real, Huelva", Cuadernos del Suroeste 2: 99-129.

— (1995): "Poblados, centros mineros y actividades metalúrgicas en el cinturón ibérico de piritas durante el Bronce Final”, Tartessos 25 Años Después (1968-1993): 417-446. Jerez de la Frontera, Ayuntamiento de Jerez.

_ y FRÍAS, C. (1989): "La necrópolis de La Parrita (Nerva, Huelva) y los inicios de la metalurgia de la plata en las minas de Río Tinto", Cuadernos del Suroeste 1: 11-21.

PINGEL, V. (1975): "Zur Vorgeschichte von Niebla (Prov. Huelva)", Madrider Mitteilungen 16: 111-136.

ROTHENBERG, B.; ANDREWS, P. y KEESMANN, I. (1986): "Monte Romero September 1986 -the discovery of a unique Phoenician silver smelting workshop in southwest Spain", IAMS 9: 1-4.

ROVIRA, S. (1995): “De metalurgia tartésica”, Tartessos 25 Años Después (1968-1993): 475-506. Jerez de la Frontera, Ayuntamiento de Jerez.

RUA FIGUEROA, R. (1859): Ensayo sobre la historia de las minas de Riotinto. Madrid.

RUIZ-GÁlVEZ, M. (1995): "Cronología de la Ría de Huelva en el marco del Bronce Final de Europa Occidental”, en Ruiz-Gálvez, M. (ed.): Ritos de Paso y Puntos de Paso. La Ría de Huelva en el Mundo del Bronce Final Europeo, en Complutum (Extra 5): 79-83.

RUIZ MATA, D. (1989): "Huelva: un foco temprano de actividad metalúrgica durante el Bronze Final", en Aubet, M.E. (Coord.), Tartessos. Arqueología Protohistórica del Bajo Guadalquivir: 209-243. Sabadell, Ausa.

(1993): "Fenicios en la bahía gaditana. El Castillo de Doña Blanca (El Puerto de Santa María, Cádiz)", Arana, R. y otros (Eds.), Metalurgia en la Península Ibérica Durante el Primer Milenio a.C. Estado Actual de la Investigación: 167-188. Murcia, Universidad de Murcia.

(1994): "La secuencia prehistórica reciente de la zona occidental gaditana, según las recientes investigaciones", en Campos, J.M., Pérez, J.A. y Gómez, F. (eds.): Arqueología en el Entorno del Bajo Guadiana. Actas del Encuentro Internacional de Arqueología del Suroeste: 279-328. Huelva, Grupo 5.272 del PAI-Universidad de Huelva.

— y FERNÁNDEZ JURADO, J. (1986): "El yacimiento metalúrgico de época tartésica de San Bartolomé de Almonte (Huelva)", Huelva Arqueológica VIII.

SCHULTEN, A. (1952): Fontes Hispaniae Antiquae VI. Barcelona, Universidad de Barcelona.

UNTERMANN, J. (1985): "Lenguas y unidades políticas del Suroeste hispánico en época prerromana", en C. Wentzlaff-Eggebert (ed.): De Tartessos a Cervantes: 1-40. Böhlau Verlag Köln Wien. 


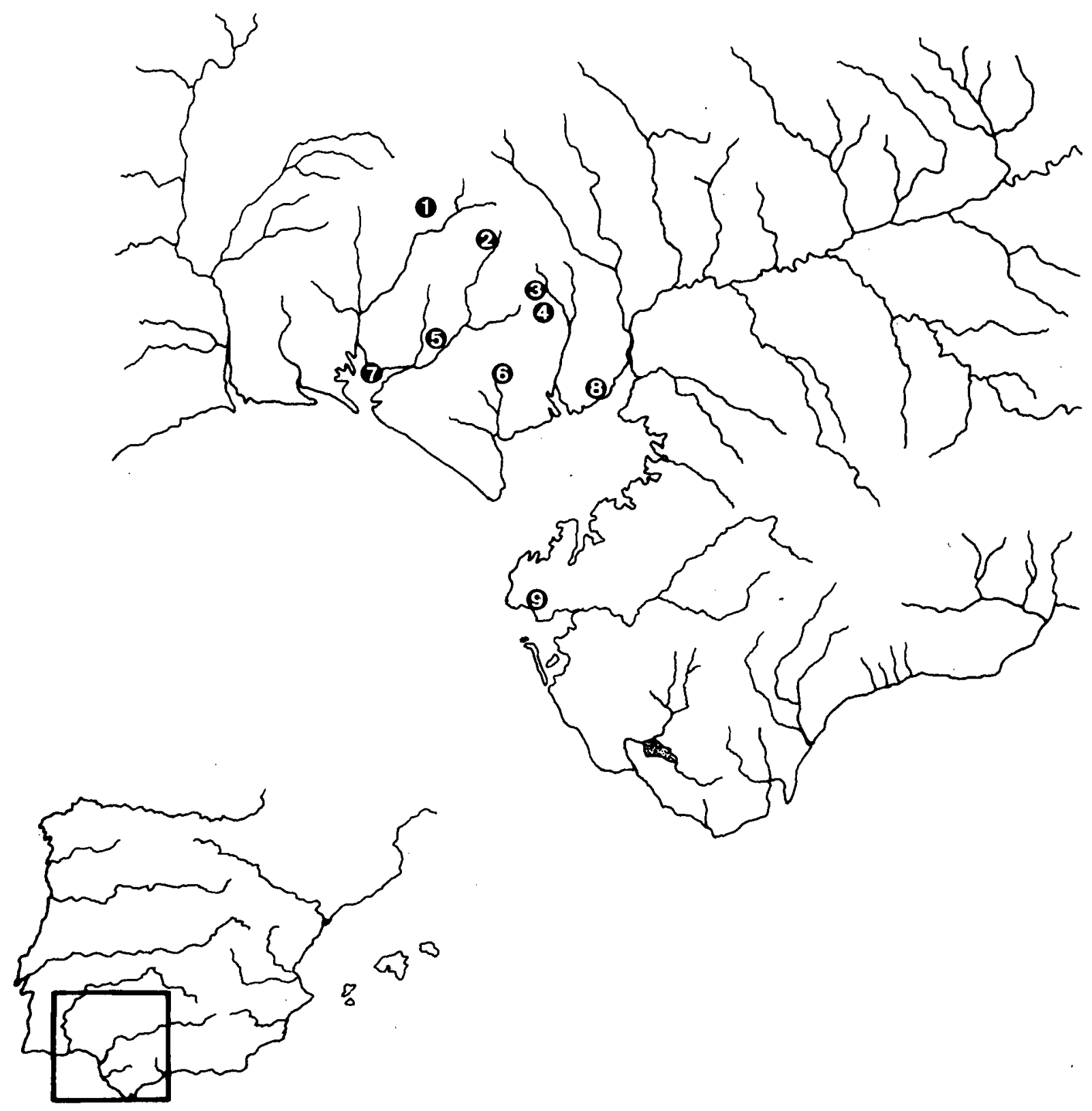

Fig. 1: Mapa de situación de los yacimientos y reconstrucción de la antigua línea de costa: 1) Monte Romero, 2) Riotinto, 3) Tejada la Vieja, 4) Peñasola, 5) Niebla, 6) San Bartolomé, 7) Huelva, 8) Cerro de la Albina y 9) Campillo 